For

PHYLOGENETIC RELATIONSHIPS AMONG SUBSURFACE MICROORGANISMS

U.S. Department of Energy Contract No. DE-FG02-90ER60989

(Awarded June 1, 1990, 1991)

to

Rensselaer Polytechnic Institute

(Sandra A. Nierzwicki-Bauer)

\title{
DISCLAIMER
}

This report was prepared as an account of work sponsored by an agency of the United States
Government. Neither the United States Governt Government. Neither the United States Government nor any agency thereof, nor any of their employees, makes any warranty, express or implied, or assumes any legal liability or responsiprocess disclosed, or represents that, or usefulness of any information, apparatus, product, or ence herein to any specific commercial pred would not infringe privately owned rights. Refermanufacturer, or otherwise does not necessuct, process, or service by trade name, trademark, mendation, or favoring by the United States Gonstitute or imply its endorsement, recomand opinions of authors expressed herein United States Government or any agency thereof. 


\section{PROJECT' DESCRIPTION}

This project irvolves the development of group-specific, $16 \mathrm{~S}$ ribosomal RNA-targeted oligonucleotide hybridization probes for the rapid detection of specific types of subsurface microorganisms (e.g., groups of microbes that share certain physiological traits). Because portions of the 165 rRNA molecule are unique to particular organisms or groups, these unique sequences can serve as targets for hybridization probes with varied specificity. Target sequences for selected microbial groups will be identified by analysis of the available rRNA sequence data for subsurface microbes. Hybridization probes for these target sequences will be produced and their effectiveness and specificity tested with RNA cell blot and in situ hybridizations. Selected probes will then be used to study phylogenetic relationships among subsurface microbes and to classify these organisms into the specific groups that the probes are designed to detect. This work will initially be performed on the P24 and C10 borehole isolates from the Savannah River site. As time permits, isolates from other DOE sites, obtained during the transitional phase, will be classified. of particular interest will be the relatedness of microbes in different geologic formations at each site and of microbes from different sites. This will provide information on the vertical and horizontal diversity of the microbss. The probes will also be used, with in situ hybridizations, to detect and monitor selected microbial groups in laboratory macrocosms and freshly collected subsurface samples. The in situ hybridizations will permit detection of selected microbial types vithout the necessity to isolate and culture them in the laboratory.

During Year 3 (June 1992-May 1993) we will concentrate on the objectives listed below:

- Continue analysis of $16 \mathrm{~S}$ rRNA sequence data (as it becomes available from $D$. Balkwill).

- Identification of target sequences and design of group-specific probes. 
- In situ and RNA cell blot hybridizations with isolates from the P24 and C10 borehole.

- Complete development of in situ hybridization techniques for microbes released from sediment samples.

This report summarizes the progress made in our laboratory from 6/1/91-12/1/91 ( 6 months), toward completion of the experimental plan for our ongoing DOE grant project entitled "Phylogenetic Relationships Among Subsurface Microorganisms" (DOE Contract No. DE-FG02-90ER60989).

\section{SCHEDULE OF MAJOR RESEARCH ACTIVITIES}

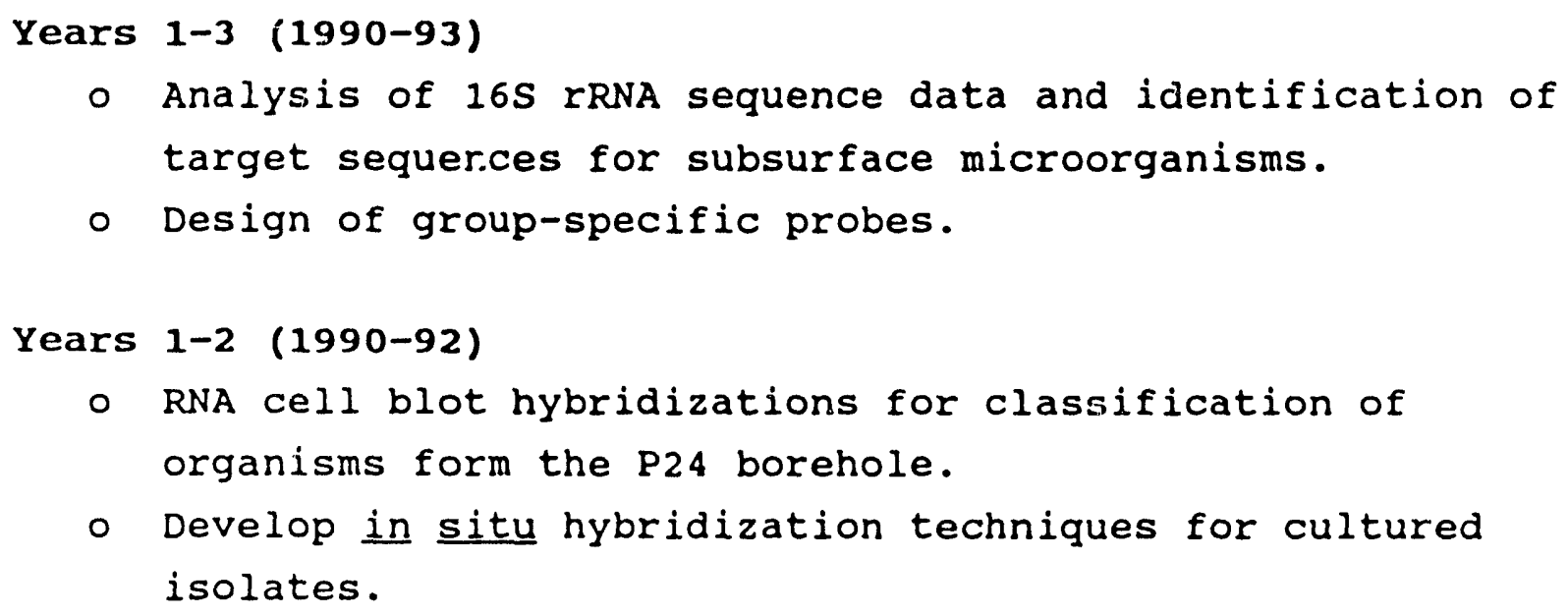

- Classification of organisms from the C10 borehole.

- Detection of $16 \mathrm{~S}$ rRNA in starved cells following introduction of nutrients.

- In situ detection of microbes released from sediment samples and monitoring of bacteria in simulated macrocosms.

\section{PROJECT OUTPUT: MAJOR ACCOMPLISHMENTS (6/91-12/1/91; 6 months)}

\section{- Probe development (design and synthesis)}


the basis of published 165 rRNA sequence data from the Ribosomal Database project. These probes are directed against common soil bacteria, that are likely to be components of the sMCC. The groups of micruorganisms that these probes are designed to detect are listed below:

1. Agrobacterium tumefaciens

2. Azospirillum lipoferum

3. Bacteroides fragilis and related species

4. Arthrobacter simplex

5. Alcaligenes faecalis and A. xylosoxidans

6. Alcaligenes eutrophus

7. Arthrobacter globiformis

8. Micrococcus luteus

9. Pseudomonas cepacia

Synthesis and testing of these probes is currently in progress. In addition to th: aforementioned probes, we have previously (June 1990-May 1991) syrthesized and tested the probes listed in Table I. Comparative sequence analysis using all known $16 \mathrm{~S}$ rRA sequences contained in the Ribosomal Database Project (473 sequences) has indicated the specificity of these probe sequences. This information is also included in Table I. Partial 16S rRNA sequence data for 24 subsurface microorganisms isolated from different depths at the Savannah River site were obtained during the first year of this grant. Additional 16S rRNA sequence data for selected SMCC isolates should be sent to us shortly (D. Balkwill, personal communication).

\section{- Rapid classification of subsurface microorganisms using in situ hybridizations}

We have initiated rapid screening of many of the subsurface microbial isolates obtained from the P24 borehole at the Savannah River site. The probes directed against Ps. aeruginosa, Ps. testosteroni and $\underline{A}$. calcoaceticus have been used for this work. organisms from the P24 borehole were selected for our initial studies because biochemical and physiological information regarding these 
isolates is available and RFLP studies involving subsets from this group are currently in progress (Balkwill \& Reeves). To date, we have screened approximately $50 \%$ of the isolates obtained from the P24 borehole. Organisms from each of the geological formations and depths at the P24 borehole are included in this group. Of these, 298 of the isolates have been classified using the probes PPA, PPT or PAC. The results obtainec from these analyses are summarized in Figure 1 and Figure 2. The most important findings from these data are indicated below each figure. Once screening is complete these data will be summarized and correlated with the results of RFLP analyses, biochemical/ physiological tests, and geological information. Isolates from the $\mathrm{ClO}$ borehole will also be screened to provide information regarding microbiological heterogeneity and horizontal diversity amongst isolates from the P24 and C10 boreholes.

\section{- In situ hybridization procedure}

Conditions for in situ hybridizations have been optimized. Numerous variables which were thought to have an effect on the results of hybridizations were tested. The results of this work have been submitted to Biotechniques for publication. An abstract of this work follows:

A rapid method for the identification of bacterial cells using 165 rRNA-directed, fluorescently-tagged oligonucleotide probes has been developed. The parameters evaluated for their effect on labeling intensity include type of fixative, time of fixation, treatment time with methanol/formaldehyde and treatment time with borohydride. The results of tests using a variety of microorganisms, both gram-positive and gram-negative, are presented. Using this method, cells are spotted onto slides and stored (desiccated) until hybridization. This method may be especially applicable to environmental samples which comprise diverse cell types and frequently require storage prior to examination. 
To facilitate rapid screening of SMCC isolates, a cell blot hybridization procedure was developed. This procedure is similar to colony lift techniques, with the exception that RNA, rather than DNA, is being detected. One major advantage of this technique over in situ hybridization with whole cells using epifluorescence microscopy is that ninety-six cultures can be screened at one time on a single blot (microscopic examination of 96 slide hybridizations would require a greater amount of time and effort).

A manuscript describing this work is in preparation.

\section{- Detection of $16 \mathrm{~S}$ IRNA in starving cells after nutrient addition}

Preliminary experiments were carried out to determine whether the use of specific nutrients by subsurface microorganisms can be evaluated using probes directed against $16 \mathrm{~S}$ rRNA. These experiments demonstrated that, $16 \mathrm{~S}$ rRNA was rapidly synthesized upon the addition of nutrients to 4-day starved cultures of $\underline{E}$. coli, as well as three of the SMCC isolates. Recently, we have modified these experiments to show that $16 \mathrm{~S}$ rRNA is detectable only in those organisms that are capable of metabolizing a specific nutrient. Pseudomonas cepacia and Acinetobacter calcoaceticus were used as test organisms for several reasons: (i) they are indigenous to sediments, (ii) they have distisct morphologies, and are therefore easily differentiated, in situ, (iii) they have different nutritional requirements, which allows for the selection of nutrients specifically used by only one organism; and (iv) we have developed 16S rRNA-specific probes for both organisms. Cultures were starved for six weeks prior to the addition of nutrient broth (at concentrations of $0.1 \%$, $1 \%$ or 10\%), glucose (at concentrations of $0.1 \mathrm{mM}, 1 \mathrm{mM}$ or $10 \mathrm{mM}$ ) or, as a control, phosphate buffered saline. The results of these experiments showed that the two species examined responded differently to the addition of nutrient broth: within 4 hours after the addition of nutrient broth to the cultures, Ps. cepacia had synthesized large amounts of rRNA, whereas $\underline{A}$. calcoaceticus had not. These results reflect the 
fact that, certain cell types (i) starve "better" than others and (ii) adapt to new nutrient situations at different rates. Because it is important to establish that a specific nutrient is utilized independently of time, we are presently investigating the possibility of using nalidixic acid to inhibit bacterial growth, while allowing synthesis of rRNA. Using this technique, the number of cells in a given sample will remain constant, and incubations can be carried out for an extended period of time, allowing the adaptation of all bacterial types to the new nutrient. It is expected that, the addition of glucose will stimulate the synthesis of rRNA only in Ps. cepacia, because this species can utilize glucose as a source of energy, whereas $\underline{A}$. calcoaceticus can not utilize this carbon source. once the optimal conditions for incubation are established, these types of studies will be extended to include sediment samples, as well as the readdition of other nutrients. 


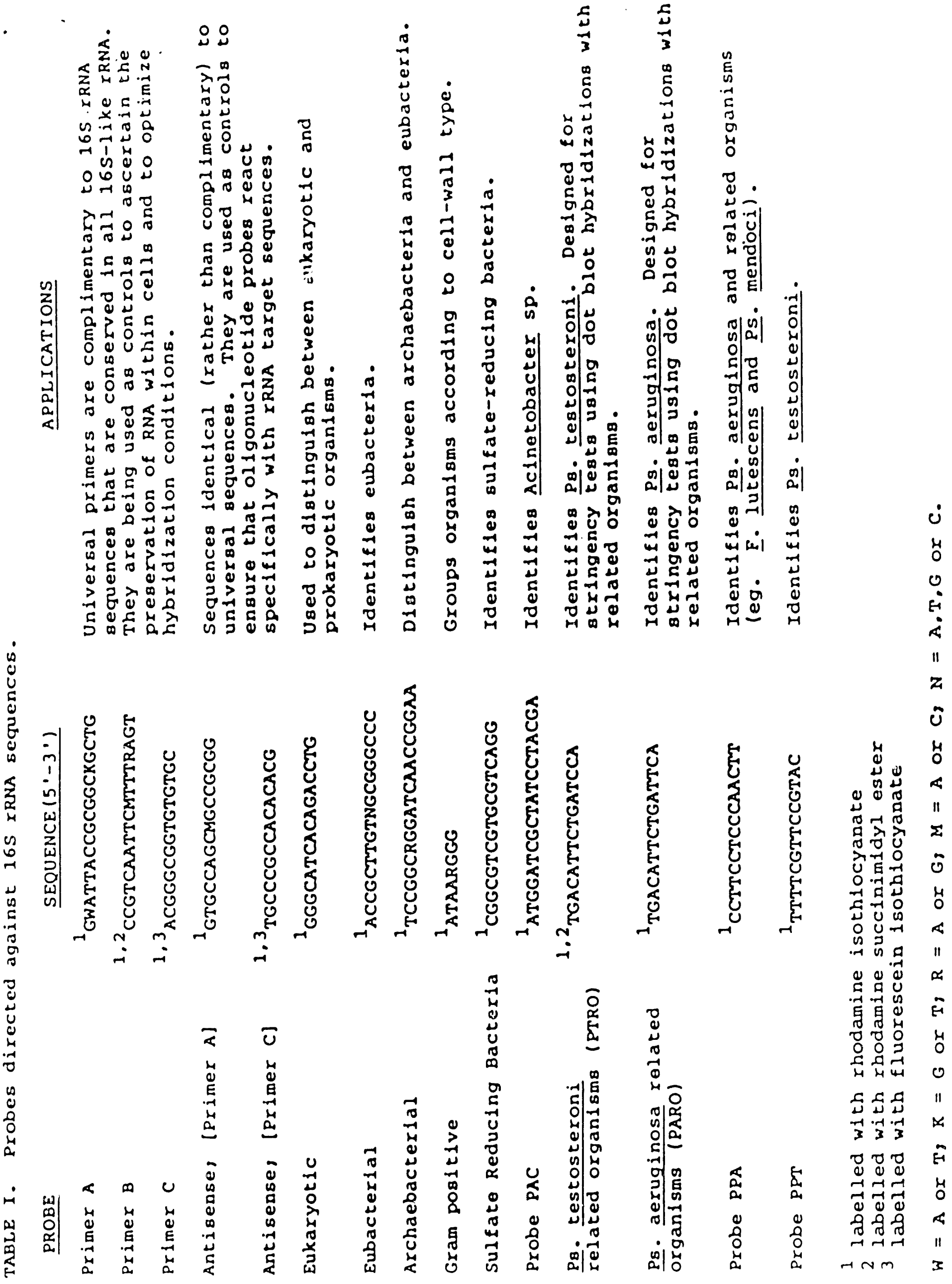


FIGURE 1. Classification of P24 borehole isolates using probe (PAC) that identifies Acinetobacter calcoaceticus.

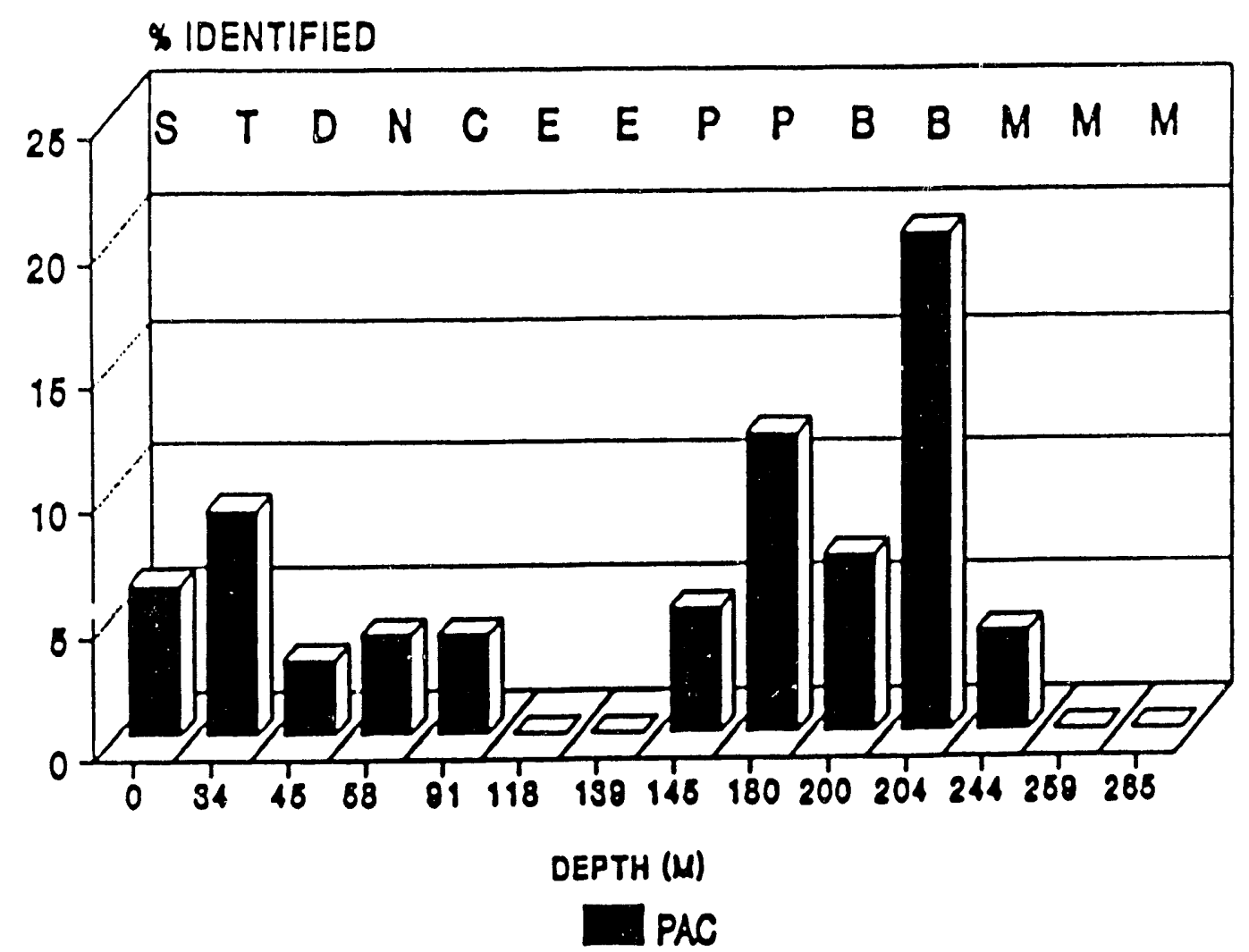

Geological Formations: $S=$ Surface Soil; $T=$ Tobacco Road; $D=$ Ury Branch; $\mathrm{N}=$ McBean; $\mathrm{C}=$ Congaree; $\mathrm{E}=$ Ellenton; $\mathrm{P}=$ Pee Dee;

$\mathrm{B}=\mathrm{Black}$ Creek; $\mathrm{M}=$ Middendorf.

Conclusions from Data:

* There is no direct relationship betreen increasing depth and the percentage of a particular organism found.

* The percentage of a specific type of microorganism can vary within a single geological formation.

* Apparently the sainpling techniques employed did not result in vertical transport of microorganisms throughout the borehole. 
FIGURE 2. Identification of $\mathrm{P2}$ borehole isolates.

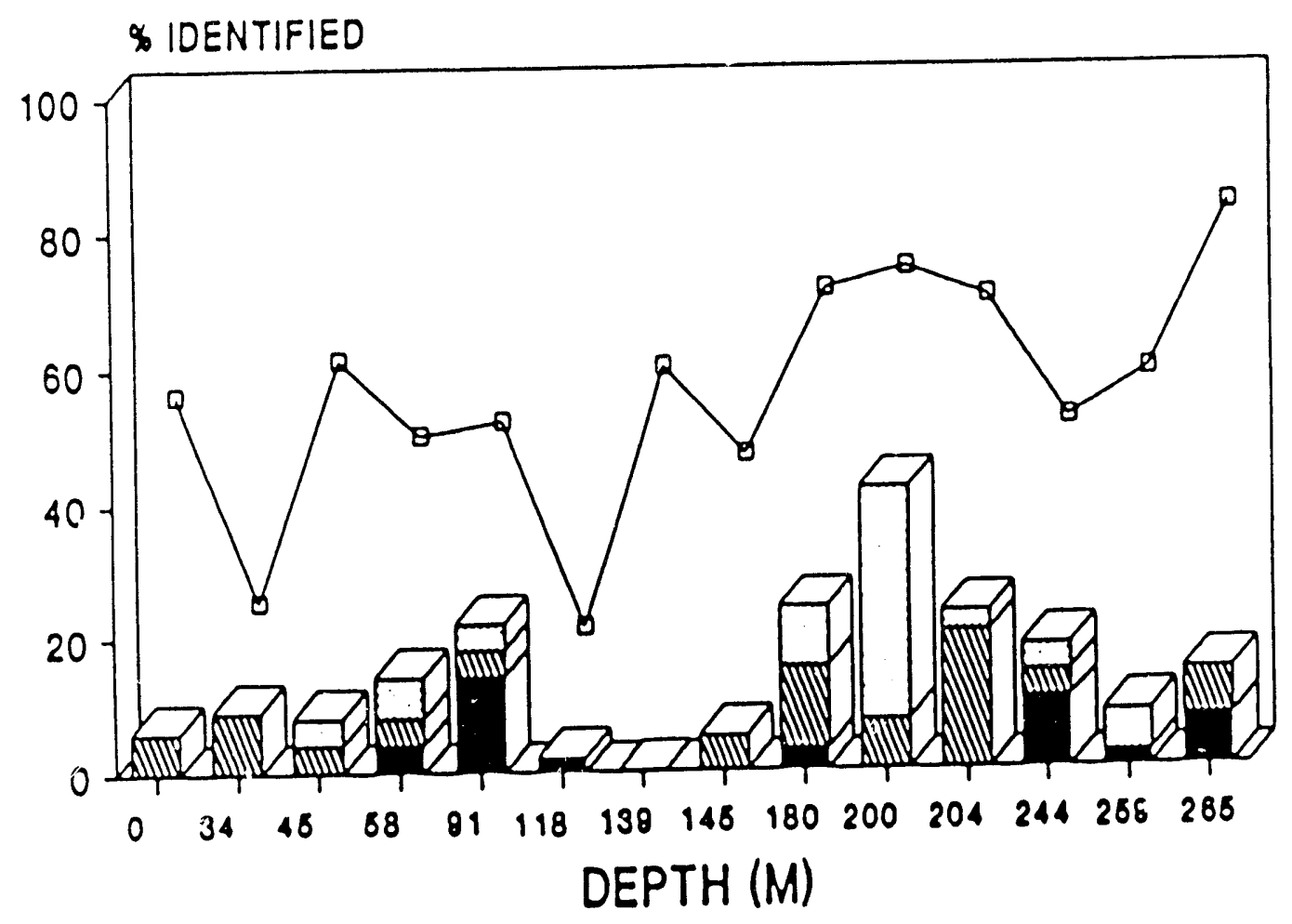

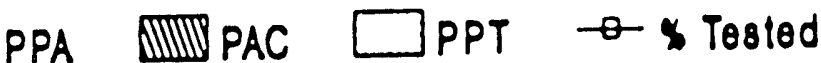

PPA: Percentage of isolates identified as Ps. aeruginosa and related crganisms, including PS. fluorescens, PS. mendoci and $\mathrm{E}$. lutescens.

PAC: Percentage of isolates identified as A. calcoaceticus.

PPT: Percentage of isolates identified as Ps. testosteroni.

$\because \&$ Tested: The percentage of SMCC isolates tested from a given depth.

Major conclusion:

* The percentage of the three types of organisms identified at a single depth or geological formation varied independently of one another. 

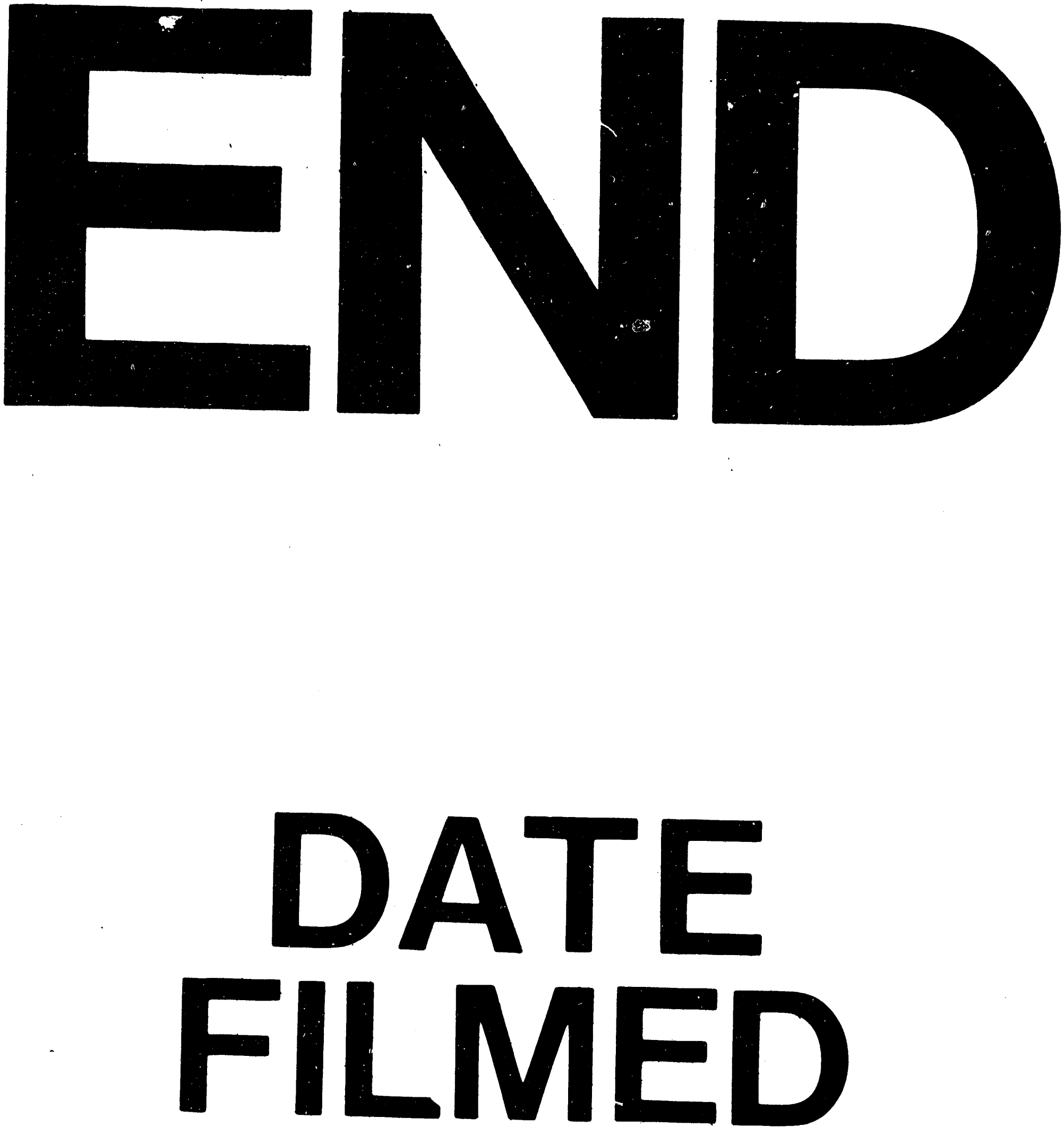

0112492 
